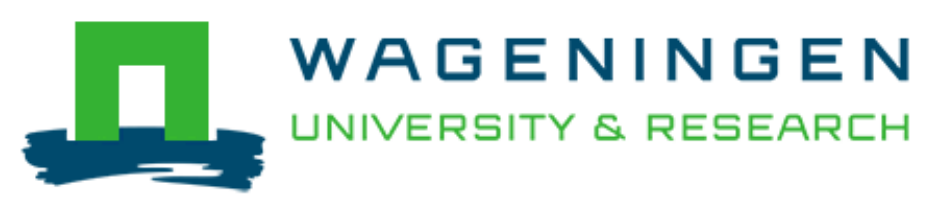

\author{
Mitigating land pollution through pesticide packages - The case of a \\ collection scheme in Rural China \\ Jin, S., Bluemling, B., \& Mol, A. P. J.
}

This article is made publically available in the institutional repository of Wageningen University and Research, under article 25fa of the Dutch Copyright Act, also known as the Amendment Taverne.

Article $25 \mathrm{fa}$ states that the author of a short scientific work funded either wholly or partially by Dutch public funds is entitled to make that work publicly available for no consideration following a reasonable period of time after the work was first published, provided that clear reference is made to the source of the first publication of the work.

For questions regarding the public availability of this article, please contact openscience.library@wur.nl.

Please cite this publication as follows:

Jin, S., Bluemling, B., \& Mol, A. P. J. (2018). Mitigating land pollution through pesticide packages - The case of a collection scheme in Rural China. Science of the Total Environment, 622-623, 502-509. DOI: 10.1016/j.scitotenv.2017.11.330

You can download the published version at:

https://doi.org/10.1016/j.scitotenv.2017.11.330 


\title{
Mitigating land pollution through pesticide packages - The case of a collection scheme in Rural China
}

\author{
Shuqin Jin ${ }^{\mathrm{a}, \mathrm{b}, *}$, Bettina Bluemling ${ }^{\mathrm{c}}$, Arthur P.J. Mol ${ }^{\mathrm{b}}$ \\ ${ }^{a}$ Research Center for Rural Economy, Ministry of Agriculture, No. 56 Zhuanta Hutong Xisi Xicheng, District Beijing, China \\ ${ }^{\mathrm{b}}$ Environmental Policy Group, Wageningen University, The Netherlands

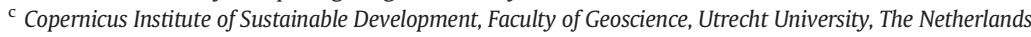

\section{H I G H L I G H T S}

- Pesticide package collection schemes are feasible in low income countries.

- Private collection schemes' environmental benefits remain ambiguous.

- Private collection schemes can shape future political economic structures.

- Governmental support is still of importance for the success of a scheme.

- Institutional arrangements with mutual resource dependency need monitoring.

\section{A R T I C L E I N F O}

\section{Article history:}

Received 14 September 2017

Received in revised form 28 November 2017

Accepted 28 November 2017

Available online 13 December 2017

Editor: Jay Gan

\section{Keywords:}

Land pollution

Pesticides

Packaging waste

China

Institutional arrangement

Waste collection
G R A P H I C A L A B S T R A C T

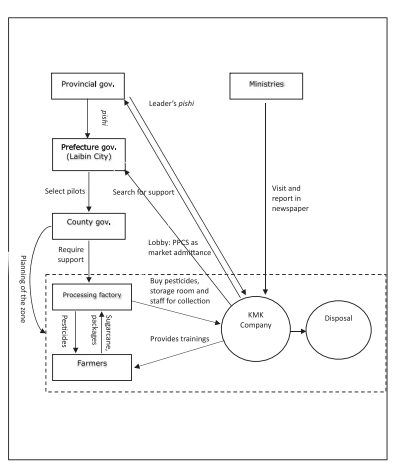

Interactions among actors in Guangxi PPCS.

\begin{abstract}
A B S T R A C T
Pesticide packages that are discarded on agricultural land can contaminate water bodies and pose a threat to the environment and human health. Little is known about how developing countries deal with this kind of land pollution. While in developed countries, packages are collected by professional organizations, the smallholder context in developing countries makes the collection of this waste much more difficult. This paper introduces and analyses a successful Pesticide Package Collection Scheme in one of the poorest regions in China, i.e. Guangxi Province. The purpose of the paper is to analyze and discuss how such a scheme can be established by multiple actors. The paper finds that the underlying success factors for establishing such a scheme are 1.) that a scheme piggy-bags on existing economic structures that reach out to farmers (e.g. associations); 2 .) that the scheme itself facilitates actors' exchange of resources to establish a temporary resource equilibrium; 3.) that all stakeholders obtain returns on their investment, even if the quality and time scale of these returns may differ. The initiation of the scheme by a pesticide company however increased both its political and market influence. Caution hence has to be paid to whether the short-term improvement in land pollution happens at the expense of a dependency on and increased use of certain kinds of pesticides.
\end{abstract}

(c) 2017 Elsevier B.V. All rights reserved.

\footnotetext{
* Corresponding author at: Research Center for Rural Economy, Ministry of Agriculture, No. 56 Zhuanta Hutong Xisi Xicheng, District Beijing, China.

E-mail address: jinshuqin@126.com (S. Jin).
}

\section{Introduction}

For several decades, China has been the largest consumer of pesticides in the world (Sun et al., 2012), with a total consumption of 1.8 million tons (trading quantity) in 2013 (National Bureau of Statistics 
of China, 2014). Accordingly, extensive research has been carried out into pesticides overuse and how pesticide use may be reduced (e.g. Hu and Rahman, 2015; Jin et al., 2015; Wang et al., 2015; Zhang et al., 2015; Liu and Huang, 2013). However, there has been a dearth of research on a problem related to the extensive use of pesticides, i.e. the disposal of empty pesticide packaging on agricultural fields. A survey by the Research Center for Rural Economy (RCRE) showed that 62\% of Chinese farmers randomly dump pesticide packages into or nearby water bodies after they applied the pesticides (Wei and Jin, 2014). It is estimated that annually, over 3.2 billion pesticide packages are discarded in such a way in China. The packaging waste weighs over 100,000 tons, and residue pesticides from these packages account for $2 \%-5 \%$ of the total weight of pesticides used (Jiao et al., 2012). The environmental harm of these discarded pesticide packages is evident: residues pollute the water and soil ecosystem, and can impact the health of humans and animals. Furthermore, most of the packages are made of plastic, which will not easily degrade, and will impact soil quality.

Research on the pollution of land and water bodies in China by waste that accrues in the process of agricultural production has so far focused on plastic mulching (Dai and Dong, 2014; Liu et al., 2014). Here, biodegradable plastics have become a viable solution (Liu et al., 2014). However, this solution is less applicable for pesticide packaging, given the nature of the plastics required. Therefore, arrangements have to be made how to collect this diffuse plastic waste so that it can be properly disposed.

Internationally, some examples exist for such collection schemes. In Brazil, in 2002, by passing Decree 4074/02, actors within the agricultural value chain (including e.g. retailers, cooperatives, government authorities, farmers) became responsible for the proper disposal of agrochemical packages. In 2009, $94 \%$ of pesticide packages were collected, which made Brazil a frontrunner in the disposal of pesticide packaging wastes (InpEv, 2011). FAO/WHO in 2008 published a guideline outlining different management schemes and existing practices to collect, recycle and dispose of pesticide packages. The guideline also lists successful schemes in developed countries such as Germany, Canada, Australia, and France (FAO/ WHO, 2008). In these countries, packages are collected by professional organizations like companies or associations which were jointly established with pesticide companies. However, not much research, to the authors' knowledge, has been conducted on schemes where pesticide packaging collection is foremost undertaken by individual farmers. These schemes are likely to be more relevant in smallholder contexts that require more decentralized collection structures.

Literature confirms that without such schemes, pesticide packages are likely to lead to land and water pollution. Damalas et al. (2008) provide an overview of farmers' disposal practices in a region in Greece, and find evidence of farmers either dumping empty containers in the field, or throwing them near or into irrigation canals or streams, if not burning them in open fires. Similar findings are reported for Oman (Said Al Zadjali et al., 2013), Vietnam (Pham Van Hoi et al., 2009), South Africa (Dalvie et al., 2006), Ethiopia (Mengiste et al., 2015, 2016) and Tanzania (Nonga et al., 2011). These studies reveal that especially in developing countries, the problem of pesticide package collection has not been tackled yet.

Despite the severity of the problem in China, so far not much research has been conducted. The only publication in English that looks into the question of land pollution through pesticide packaging is Yan (2014). In her dissertation, Yan shows that about three-quarter of surveyed vegetable farmers in Hunan Province, China, dispose of pesticide packages in the field. Otherwise, a search of Chinese journals online $\mathrm{CAJD},{ }^{1}$ using "topic $=$ (pesticide packaging wastes) $\mathrm{OR}$ (pesticide package)" within the "Core Journals" returned only seven papers, from

${ }^{1}$ CAJD (China Academic Journal Network Publishing Database) is the largest database of Chinese academic journals. Almost all papers published in China's journals since 1915 are included. Similar with (Social) Sciences Citation Index, the "Core Journal" is the list which includes the most influential journals based on their quality and citations. Search date is 04-11-2015. which the earliest paper was published in 2010. Of the seven papers, Cai (2013) presents the results of a survey about farmers' Willingness to Accept different kinds of pesticide package collection schemes. He and Jin (2013) analyze international experiences of pesticide package collection schemes, while Wei and Jin (2014) present the case of Shanghai's pesticide collection scheme. In Shanghai, as the richest region in China and with a rather low share of agriculture $(0.6 \%$ of its regional GDP in 2013), public finance has subsidized up to $80 \%$ of farmers' costs on pesticides. Under this scheme, farmers only receive pesticide subsidies if they return empty packages to the governmental collection station. As reported by Wei and Jin (2014), it is unlikely for other parts of China to learn from Shanghai as the low share of agriculture in regional GDP and Shanghai's overall economic development are hardly representative for the rest of China.

Not only is there a lack of academic attention to pollution from pesticide packages, Chinese policy so far has paid little attention to this problem. In China, the problem of agricultural plastic waste in rural areas has only recently become the object of policy-making. A review of Chinese government documents (e.g. including laws, regulations, governmental announcements) revealed that pesticide packaging waste was first dealt with, on a national level, in 2011, i.e. by the "Technical guideline on environmentally safe application of pesticides", a voluntary guideline issued by the Ministry of Environmental Protection (MEP). This guideline stated that "pesticide containers cannot be used for other purposes, and intact containers can be collected by the retailers or producers". A document issued by the State Council in 2013 states that one of the major tasks to protect soils is "to establish recycling systems for pesticide packages" (State Council, 2013).

Given this dearth of research and policy on collection schemes in China, this article looks at the case of a pesticide packaging waste collection scheme that was set up in Guangxi Province, China. The government of Guangxi is relatively poor and therefore may not necessarily have the means to devise a Pesticide Package Collection Scheme (PPCS) based on subsidies and governmental investment, as in the case of Shanghai. Therefore, the involvement of a private company became pivotal in Guangxi. In this article, we will hence focus on the set up, institutionalization and outcomes of this scheme. We will particularly analyze how actors' investment of different kinds of resources has led to the institutionalization and particular design of the scheme.

The remainder of the paper is organized as follows. Section 2 introduces the study site and outlines the methodology employed. Section 3 shows the result of the Guangxi case. Section 4 discusses the case and draws conclusions.

\section{Material and methods}

\subsection{Study site}

The research was carried out in Guangxi Zhuang Autonomous Region (Guangxi) in the south of China. Guangxi is one of the most underdeveloped provinces. In 2013, the Per Capita Gross Regional Product of Guangxi was 30,588 RMB. In terms of development the province ranks 27th out of 31 provinces, with only Tibet, Yunnan, Gansu, and Guizhou having a lower Per Capita Product (NBS, 2014). Agriculture is the province's primary economic sector and accounts for $16.3 \%$ of its Gross Regional Product.

The PPCS was initiated by a private pesticide company, with the participation of sugarcane farmers. Guangxi is called the 'Capital of Sugar' and is the most important sugar producing province in China, accounting for $67 \%$ of the sugar produced in China. Sugarcane is the province's most important cash crop. The sown sugarcane area accounts for $25.2 \%$ of the total farming area of the province.

The research was carried out foremost in Laibin Prefecture as this was the first local government that agreed to develop a PPCS with the pesticide company KMK. And two towns (Xiaopingyang Town and Qiaogong Town, both were the first to participate the scheme) were 
further selected for case study. The field work was carried out in the beginning of 2014 .

\subsection{Methods for data collection}

A case study approach was applied, which allows studying a social phenomenon through a thorough analysis of an individual case (Kumar, 2005, 103). Such kind of analysis can be particularly useful when researching new kinds of phenomena, as e.g. Pesticide Package Collection Scheme in Guangxi.

Primary data was collected during a field visit in March and April 2014. In-depth interviews, focus group meetings and a farmer survey were carried out with related actors on site. The research steps were as follows:

(1) Focus Group Meetings: To get an overview of the PPCS in Guangxi, 3 group meetings were held both at the prefecture and district (county) level with the help of the provincial agricultural bureau. Participants included: the deputy mayor of Laibin Prefecture; 12 officials from the extension service of Agricultural Bureau, the Environmental Protection Bureau, the Sugar Industry Administration Bureau, and the "Beautiful Laibin Construction Office" (an office that was set up by the Guangxi Government and is responsible for the coordination of activities under the "Beautiful China construction" program of the 18th National Congress of the Communist Party of China); also 4 managers of the local sugar processing factories were present, as well as the manager of the pesticide company KMK (see below). Notes were carefully taken during the meetings. Through coding of the records, the history, technical process, roles of different actors and their resource investment and gains were obtained.

(2) In-depth interviews: To gain a better understanding of the implementation of the PPCS, and to validate information from the focus group meetings, 3 in-depth interviews were carried out with the General Manager of KMK and the technical manager. Notes were taken during the interviews, and were triangulated with information from focus group meetings.

(3) Farmer survey: We collected 46 questionnaires from farmers of two towns, among which 19 from Xiaopingyang Town and 27 from Qiaogong Town. The sample is a stratified random sample as farmers were selected according to their scale of sugarcane planting to ensure the sample includes all farm scales. Descriptive statistics are used to understand whether and how farmers' behavior changed after joining the scheme.

(4) Document analysis: We also collected and analyzed governmental documents including red-head documents, five year plans and statistical yearbooks, and also annual reports of the pesticide company KMK.

From the above, we can see that the actors of the institutional arrangement are government agencies, the pesticide manufacturer, farmers, the extension service (agricultural bureau), as well as the sugar cane processing industry. To some extent these actors correspond to the actors identified by FAO (2008), only that FAO's waste management and recycling organizations are not included because we focus on the collection of pesticide packages which are defined as hazardous waste by law and cannot be collected by common waste recycling organizations. Agricultural colleges and schools, NGOs or farmer cooperatives, which are also listed in FAO (2008), do not play a role in the case, and therefore are not included in the analysis.

\subsection{Theoretical framework}

The above mentioned scheme will be analyzed taking an "institutional arrangement" approach as employed by Li et al. (2014) and as originally developed by Arts et al. (2006) (Fig. 1). "Institutional arrangements" are part of actor-centered institutionalism which sees social phenomena as the outcome of interactions between intentional actors, while both actors and interactions are at the same time influenced by their institutional context (Scharpf, 2000) as this context will to some

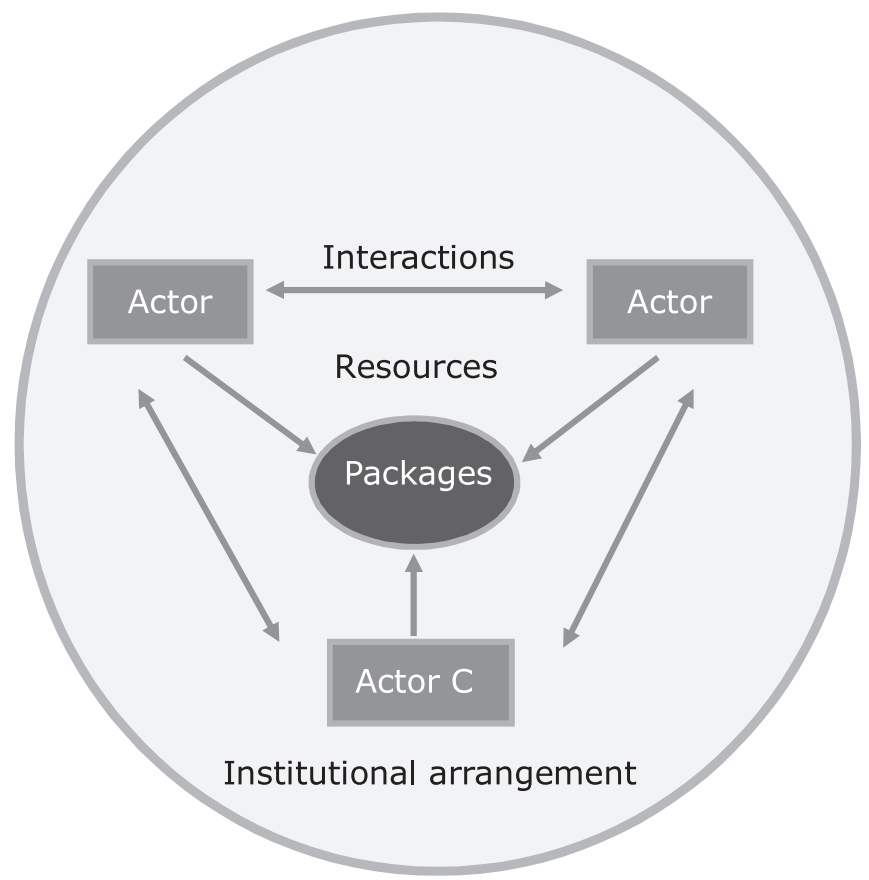

Fig. 1. "Actor-centered" framework for the PPCS.

extent define what type of actions are possible (Brandsen, 2001). Actors are assumed to engage in temporary coalitions in order to establish a scheme within the context of existing "rules of the game" (see also Arts et al., 2006). Every actor will bring into the coalition resources which the respective coalition partners depend upon. Furthermore, each actor will bring into the temporary coalition certain "views and narratives" on a problem and how to solve it (see Arts et al., 2006, 99). We will hence refer to an institutional arrangement as "a temporary stabilized actor network with resource dependencies among the actors and specific rules of the game" (Li et al., 2014, 3199). In our analysis, the "institutional arrangement" will provide the context for a more indepth analysis of the case study.

Focus of the analysis will be on the resources that actors bring to the institutional arrangement. The analysis hereby focuses on the intersection of economics and politics, i.e. at how political factors influence the economy and vice-versa. The reason for this focus is also the rather unusual situation that in Guangxi, a Chinese private company started a scheme for agricultural waste collection. If a company initiates the setting up of an institutional arrangement, it can be assumed that the company may invest resources in the beginning to eventually receive resources from other actors. These may be financial resources and/or other resources that the company may not have easy access to, with the institutional arrangement helping the company to gain access. At the same time, other actors may only get involved in an institutional arrangement, e.g. provide their time, financial resources or knowledge to set up a PPCS, if they may benefit from it. An institutional arrangement hence facilitates actors to combine and complement a variety of resources, which is also referred to as "mutual resource dependency" (Arts and van Tatenhove, 2004, 352). Hence, we assume that in our case an institutional arrangement has been successfully established if it facilitates actors to combine and compliment their resources in a way that their gains outweigh their losses. "Gains" hereby points at the institutional arrangement helping a stakeholder to better fulfill her/his organization's role of e.g. providing a public good.

Such a focus on resources has also been proposed by Brandsen (2001). According to him, actor-centered institutionalism will analyze how individual actors possess various levels of material resources and have access to different social networks. While Brandsen (2001) distinguishes two different kinds of resources, Li et al. (2014) list a variety of resources 
that may be exchanged within an institutional arrangement, e.g. financial credit/support, knowledge, access to certain groups of actors, means of communication, legal power, or access to market channels. For the case at hand, we distinguish between two resources, i.e. economic resources and socio-political resources. The latter refer to social and at times political advantages that actors obtain due to their involvement in an institutional arrangement, e.g. access to information, politicians or political committees, or an increase in reputation within a certain policy domain. These points show that when using this kind of actor based institutionalism, attention needs to be paid to the kind of resources this exchange involves and which implications the exchange has for a stakeholder in assuming his/her role and responsibilities.

In conclusion, using actor-centered institutionalism and "institutional arrangements" we structure our analysis by first describing the institutional context in which the institutional arrangement is established (i.e. the rules of the game), to then introduce and analyze the roles and interests of actors who participate in the arrangement. This introduction also includes actors' discourses and programs prior to the establishment of the scheme. Discourses here are the "views and narratives of the actors involved" (Arts et al., 2006, 99), i.e. how they define the problem at hand and the solutions they propose based on their general norms and values. "Programs" refer to actors' measures to deal with the problem at hand. Subsequently, under "stakeholder constellation" we analyze how the institutional context defines "a set of positions from which stakeholders realize the institutional arrangement" (see Bluemling et al., 2010, 558), and how the institutional arrangement facilitates actors' exchange of resources to establish a temporary resource equilibrium, showing the different resource gains and investments of each actor. Given the actor-based understanding of an institutional arrangement, it will be seen as in flux, depending on how resource exchange develops. We hence will pay particular attention to the "ongoing institutionalisation ... as a result of the interplay between the interactions of actors" (Arts et al., 2006, 97).

\section{Results}

In the following, we first briefly introduce some important traits of Guangxi Province's political economy to explain the general "rules of the game". Subsequently, actors will be described individually followed by an analysis how they combine and complement their resources within the PPCS.

\subsection{Background}

Sugar is considered a strategic agricultural product in China, next to grain, cotton, and oil. Due to its particular importance to the country, Guangxi's sugarcane sector is largely government-planned. The sugarcane price is decided by the provincial government at the start of the crushing season. The government also divides the land into sugarcane zones, and farmers of a zone can only sell their sugarcane to the sugar processing factory (SPF) of the respective zone (see Augustin-Jean, 2014, for more information on Guangxi's sugar economy). Due to this trade relationship between farmers and SPFs, the latter also play a role in the provision of agricultural inputs. When farmers buy inputs from SPFs, they do not need to pay immediately, but costs will be deducted from the final sugarcane revenues when farmers sell the sugarcane to the SPF.

Within the context of such a government-planned sugarcane sector, a private company, Kai Mi Ke agro-technical service company (KMK), entered the Guangxi market in 2009, to initiate the PPCS in 2011.

\subsection{Actors of the institutional arrangement}

The PPCS is understood to be both embedded in certain "rules of the game", i.e. the political economy of Guangxi's sugarcane industry, as well as constructed by actors that pursue certain interests with establishing the scheme. These actors will be introduced below.
(1) Kai Mi Ke (KMK)

KMK is a subsidiary company of the Hebei Haoyang Chemical Industry Group which focuses on pesticide production. Haoyang Group is a medium-sized company in China's pesticide industry, with an annual pesticide production capacity of 3000 tons (active ingredients). Established in 2009, KMK's major task is to sell the Group's pesticides to Guangxi's sugarcane sector. KMK stresses environmental protection in its marketing strategy, e.g. among its top targets are to build a 'modern green system for crop protection', and to 'protect the earth' (KMK, 2013). Consequently, different from other pesticide companies, KMK claims to sell what it calls a 'pesticide use service' which includes farmer trainings, rather than pesticide products only. According to KMK, its strategy is not to sell more pesticides to each household, but to sell pesticides to more households.

In 2011, KMK initiated the Guangxi PPCS. This scheme was the somewhat unexpected - result of an 'almost-successful-but-failed' international trade negotiation. The General Manager of KMK explained how a visit of the Group's director triggered the initiative for a PPCS.

Our boss went abroad (Brazil) to sell our pesticides. Because of the good quality of our products, he successfully persuaded a local retailer to cooperate with us. During the discussion about the details of the contract, we were required to establish a package recycling system as a compulsory obligation to sell pesticides in the country. It was the first time that my boss heard about that. Though finally we did not sign the contract because of the high costs to establish such a system abroad, my boss felt that it might also be a trend in China, and there was no company doing that. Since then, he started to search for a suitable location to establish [such a system]. And finally, we chose Guangxi for its open-minded leadership regarding new things. Hong Xu, General Manager of KMK Guangxi (personal communication, 30.03.2014).

(2) Guangxi government

Generally speaking, in Guangxi as one of the most underdeveloped provinces in China, economic development is the highest priority on the government's agenda. This is reflected in "The 12th Five Year Plan for Economic and Social Development of Guangxi" (The people's Government of the Guangxi Zhuang Autonomous Region, 2011). Modern industrial development here is listed as the first priority. Agricultural development focuses on modern agriculture and related productivity increases. Environmental protection prioritizes energy saving and resource saving, with little attention for agricultural pollution, let alone pesticide packaging wastes.

However, in the end of 2012, the concept of "Beautiful China" was put forward in the Report to the 18th National Congress of the Communist Party of China (NCCPC). To respond to the central government's initiative, Guangxi started its 'Beautiful Guangxi, Clean Countryside' action program. The PPCS was included as an important part of this action program. Accordingly, at local level, similar action programs such as the "Beautiful Laibin, Clean Countryside" were set up by the prefectural governments. Organizations named "Beautiful Guangxi Construction Office" or "Beautiful Laibin Construction Office" were established at different levels of government.

(3) Sugarcane Processing Factories (SPFs)

To encourage farmers to plant sugarcane, SPFs buy pesticides directly from pesticide companies and provide them to the farmers of their sugarcane zone. When farmers buy pesticides from a SPF, they only need to pay when they sell their sugarcane. SPFs hence to some extent mediate agricultural inputs to farmers. If an SPF includes a certain pesticide in its portfolio, a PPCS can make use of the SPF's advance payment structure. For interviewed farmers, $82 \%$ of their pesticides were bought from the SPF, and 18\% came from other sources, such as village shops. SPFs hence can be very important intermediaries for the implementation of a PPCS. Normally, depending on its processing capacity, one SPF can cover 100,000-200,000 mu (i.e. about 6667-13,333 ha), comprising 5000-8000 farm households. 


\section{(4) Sugarcane farmers}

According to the survey in two townships of Xingbin District, the average farm size is $34.3 \mathrm{mu}$ (2.3 ha), out of which $31.5 \mathrm{mu}$ (2.1 ha) are planted with sugarcane. The average household income from sugarcane is $59,284 \mathrm{RMB}$, accounting for $75.5 \%$ of the total household income. Sugarcane is a perennial crop, once planted, normally, it can be harvested for five years. The crop is labor intensive as it is harvested manually.

\subsection{Interaction, resource investment and gains of different actors}

We first indicate how the institutional context defines the position of actors in realizing the PPCS, after which we outline how the collection system works from a technical perspective, to then analyze how resource exchanges across actors led to the implementation of this scheme. We here distinguish a pilot stage and an institutionalization stage.

\subsubsection{Stakeholder constellations}

Though the scheme was initiated by a private company, the government sets the rules of the game in the Guangxi sugarcane sector. It sets the price of sugarcane, and laid down a rather fixed trade relationship between farmers and SPFs. Due to these rules of the game, KMK interacts with several SPFs as intermediaries, rather than with thousands of farmers, and it can use the governmental agro-technical extension system to train farmers not to dispose of packages in the field.

Given this context, we can understand the positioning of different actors in the institutional arrangement. The government does not make any new rules within the PPCS, but assumes that existing rules are complied with. Any new rules brought forward by actors within the PPCS should be approved by the government. KMK, as initiator of and investor in the PPCS, designs the rules for the PPCS, and obtains approval from the government, after which these rules are integrated into governmental regulation. SPFs are rule compliers, and partner with KMK in implementing the scheme. Farmers are generally assumed to be by and large rule followers, given the government-planned nature of the sugarcane sector (see Augustin-Jean, 2014, for a discussion of the government-farmer relationship in Guangxi's sugar economy).

\subsubsection{Technical process}

Technically, the flow of collected packages is reverse to the direction of pesticides sale. KMK sells its pesticides to contracted SPFs, who sell the pesticides to their sugarcane farmers (and partly donate them for free to encourage farmers to plant and sell sugarcane). Farmers return empty pesticide packages to the collection station located at the SPF, and the SPF calls KMK to transport the packages to the hazardous waste disposal site. Currently, only KMK packages (plastic bags and bottles) are collected. For each bottle, KMK pays 0.15 RMB for the collection. For each bag, KMK pays $0.2 \mathrm{RMB}$ to the SPF. This latter amount covers 0.02 RMB for the SPF collection center's maintenance costs; 0.02 RMB for the part-time coordinator who is employed by the SFP and coordinates the collection of packages; 0.06 RMB for the village sugarcane coordinator, for collecting packages from farmers; 0.1 RMB for the sugarcane farmers. Additionally, KMK pays 14,000 RMB/ton to the hazard waste disposal company for the disposal of packages.

\subsubsection{Evolution of shared discourses (pilot stage)}

After its establishment in 2009, KMK submitted a report to the Deputy President of the provincial government in 2010. In this report, KMK emphasized the PPCS as part of its plan on Integrated Pest Management (IPM) in Guangxi. The Deputy President made positive pishi ${ }^{2}$ on the report. With this pishi, KMK started to search for cooperation partners

\footnotetext{
2 Pishi is Chinese and means that a leader writes remarks on a document which was submitted by a lower level official or department. Positive pishi from higher government levels can be seen as an important achievement in one's work. For a company, positive pishi increases the credibility of a project.
}

within district governments. In 2011, KMK successfully persuaded the government of Xingbin district, the largest sugarcane county in China, to support the PPCS. Xingbin is administered by Laibin Prefecture. Therefore, KMK motivated the Laibin Bureau of Agriculture, Laibin Bureau of Environmental Protection, and the local Sugar Industry Development Bureau to jointly submit a report to the Laibin Government to ask for approval to implement the scheme in Xingbin. Only one week after the submission of the report, the kick-off meeting was organized. To show their support, officials from agricultural and/or environmental protection departments of provincial, prefectural, and county levels attended the meeting. In officials' speeches, 'sustainable development', 'quality safety', 'environmental protection', and 'corporate social responsibility' were frequently mentioned. These terms, but also terminology from government documents (e.g. 'Beautiful Guangxi' or 'clean countryside') were subsequently highlighted in KMK's advertisement of the scheme. In the KMK annual report (KMK, 2014) on the PPCS, the cover slogan is "To prevent agricultural non-point pollution, to protect the rural environment, by starting the collection of pesticide packaging waste". During the field visit, banners with similar contents were also frequently found in villages. Shared discourses created a context for cooperation between the government and the company. The PPCS as a concrete program helped to bridge the gap between the government objective to reduce pollution in the countryside, and the company's interest to get a larger market share and increase profits. The company would not have been supported by the government if KMK just had wanted to sell more pesticides. Therefore, KMK framed its motivation in a way that the government bought into KMK's idea. Even after the scheme received appreciation by the government, KMK still praised the local government as the primary contributor to the success, e.g. KMK describes the scheme as, "government dominating, company implementing, farmers participating, and market driven" (KMK, 2014).

\subsubsection{Evolution through interaction and resource exchange among actors (institutionalization stage)}

In 2011, three SPFs in Xingbin District were involved in the PPCS. After some time, the scheme appeared to bring benefits to the different actors involved. Farmers' sugarcane fields became cleaner, which implied improvements in farmers' natural environment, and counted towards the government's "Beautiful Laibin" program. SPFs reported that, by using KMK pesticides, the sugar content of sugarcane would have improved and would allow SPFs to get more sugar from the same weight of sugarcane. Furthermore, farmers earned some money, even if not much, by returning the packages. Consequently, actors became more strongly involved in the scheme. In Fig. 2, we conceptualize the dynamics during and after the pilot stage.

The Central Government, represented by related ministries, was not substantially involved in the scheme in the pilot stage. In 2012, officials from the Ministry of Environmental Protection (MEP) and Ministry of Agriculture (MOA) visited Laibin's PPCS. China Environmental Newspaper, which is the official organ of the MEP and is published nationwide, also published an article about the scheme. Both, the local governments of Guangxi and KMK, received nation-wide attention and reputation for their initiative. In 2013, MEP invited KMK to become a committee member to write the draft of "Management Methods for the Collection and Treatment of Pesticide Packaging Wastes", which made KMK very proud, for they participated in the design of national policy.

The provincial government, in response to the call of the Central Government's Beautiful China Construction program, made a plan on "Beautiful Guangxi Construction" in 2013, in which 10 projects were listed that deal with keeping the countryside tidy. The PPCS was listed as the first of the 10 projects. Even if the government does not pay for the scheme, it can still make it a political achievement when it reports to the Central Government. For KMK, but also for the governments of Xingbin district and Laibin Prefecture, it is a significant success that 


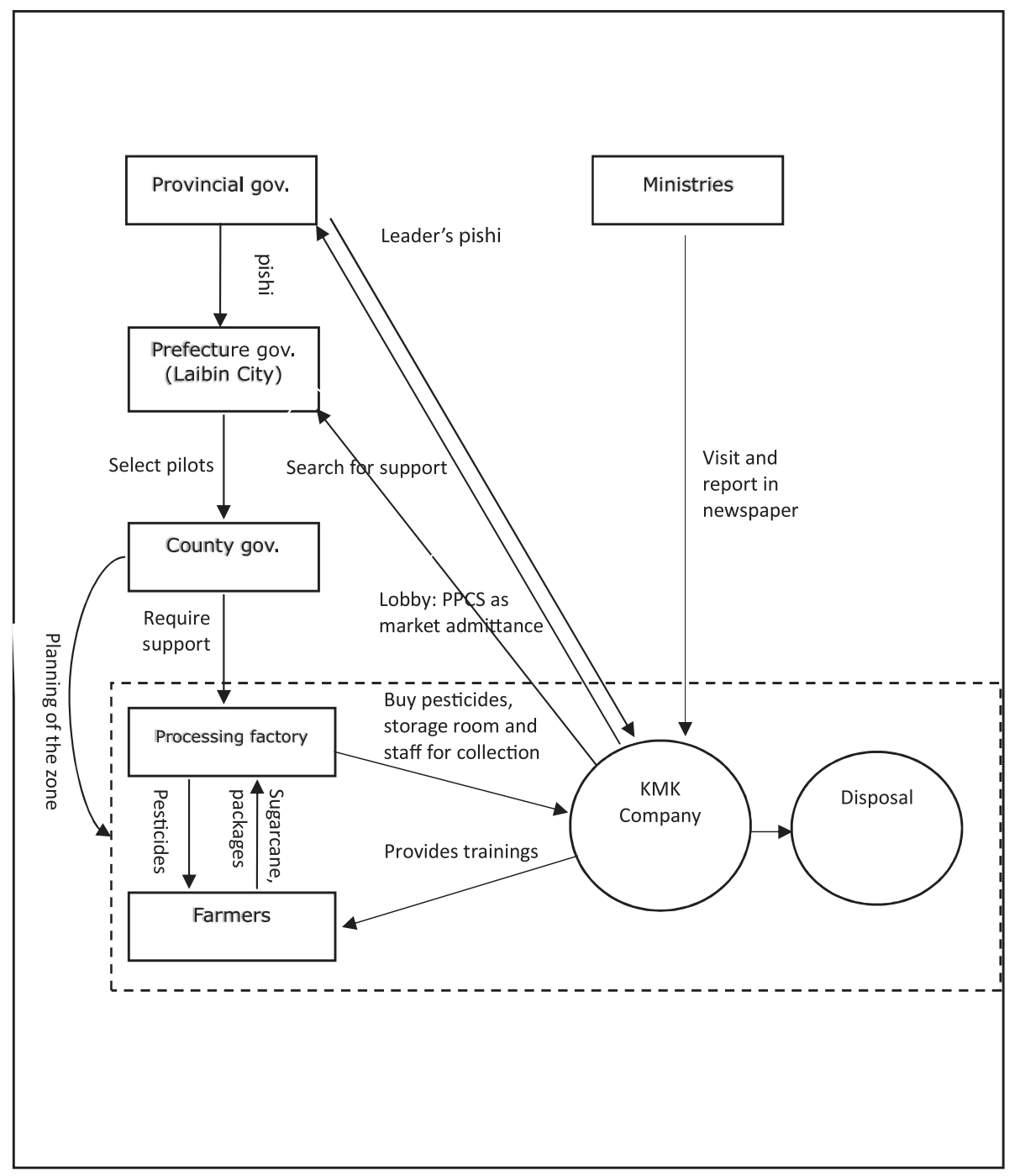

Fig. 2. Interactions among actors in Guangxi PPCS.

the scheme is included in provincial planning. According to Hong Xu, General Manager of KMK Guangxi: "The inclusion in the Plan makes the PPCS more formal and official".

The positive feedback from the provincial government strengthened the confidence of Laibin Prefecture in the PPCS, so that the prefectural government started to encourage more SPFs to join the scheme. They issued several "Red-head Documents" 3 to request the county and township governments and SPFs to support KMK. For most local Red-head Documents related to the PPCS, KMK wrote the first draft. Within the Red-head Document, KMK is often listed as one of the major actors, together with Bureaus of Agriculture and other governmental actors.

Since the county government is responsible for dividing and allocating the sugarcane zones, it can easily get support from SPFs. However, for SPFs, to join the PPCS was not only a way to show support to the government, but was also seen as an opportunity to increase profit. As mentioned earlier, SPFs reported that KMK pesticides would improve sugar content.

Farmers can get some monetary compensation for little effort. According to the survey mentioned above, in 2013 each household

\footnotetext{
3 Similar with pishi, a Red-head Document, hongtouwenjian, is neither a law nor a regulation, but a frequently applied instrument in China with a strong administrative color. Normally, if the government wants to push something forward, it can issue a red-head document, which, to some extent, might be more 'effective' to get an immediate outcome than a law or regulation.
}

received on average 22.2 RMB for returning pesticide packages. The survey also showed a change in farmer behavior and attitude with regard to the dumping of packages. Over $85 \%$ of interviewed farmers indicated that even if they were not compensated, they still would return packages. Many of them hope that all packages, including those from other companies than KMK, can be collected, not only to increase their monetary compensation, but also to have cleaner fields. A further benefit for farmers is that KMK usually works together with the local extension station, to provide training and services with regard to pesticide use. As a result, over $63 \%$ of the interviewed farmers indicated to have reduced their pesticide use.

KMK gained much from the scheme in terms of public reputation and establishing a working relationship with governmental departments of different levels. However, the company did not obtain immediate economic benefits from environmental protection activities for which it nevertheless paid more than 4 million RMB. This imbalance may only to some extent be explained by the company's argument that it set up the scheme as part of its Corporate Social Responsibility. By carrying out the PPCS, and especially after getting official support from the government, more and more SPFs joined the scheme. These SPFs increased their purchase of pesticides from KMK. Taking Xiaopingyang SPF as an example, in 2011, the year the factory joined the scheme, it bought 200 tons of pesticides from KMK. After the factory verified that KMK pesticides indeed improved sugar contents, and also for the sake of establishing relationships with KMK, in 2013, 
Xiaopingyang SPF bought 520 tons of KMK pesticides, accounting for more than half of the total amount of its pesticides purchase. The other pesticides which are not bought from KMK come from pesticide suppliers with long-term contracts from the past. However, the general trend is that SPFs are buying more pesticides from KMK in counties where the PPCS was implemented. In 2011, KMK pesticides covered 3.43 million $\mathrm{Mu}$ (=228.667 ha) of sugarcane fields. In 2012 and 2013, this area increased to 4.73 million $\mathrm{Mu}(=315.333 \mathrm{ha})$ and 6.27 million $\mathrm{Mu}$ (= 418.000 ha), respectively (KMK, 2014). KMK considerably enlarged its market share in Guangxi, and therewith increased its turnover and profits.

\subsubsection{Resource distribution within the PPCS}

As became clear from the analysis, all actors involved in the PPCS gained from it, albeit in different ways. Especially KMK is no longer only coordinating the collection of packages and paying for the scheme. KMK plays a central role throughout the whole process in establishing the institutional arrangement.

Table 1 provides a summary of resource investments and resource gains from the PPCS for each actor. As mentioned above, we divide resources into two categories, namely financial and social-political resources. From the table, we can see how resources, to varying degrees, "balance out" across actors. The most straight-forward is the financial balance where one actor invests financial resources and other actors gain these resources. The interesting part is where an actor invests financial resources and gains social-political resources, as in the case of KMK, where its investment realizes financial resource gains for e.g. farmers, coordinators and policy makers. We here understand that KMK's socio-political gains will be realized as financial gains at a later point, e.g. KMK's participation in writing and discussing MEP "regulation" has brought KMK advantages in comparison to its competitors in the pesticide market. KMK does believe that once the collection of packages becomes a legal responsibility, rather than only a social responsibility, and the cost of the PPCS is an internal cost of all pesticide companies, the existing PPCS will transfer to a key advantage of KMK, compared to its competitors who have never set up such a scheme.

In conclusion, an institutional arrangement has been successfully established because the PPCS facilitates actors to combine and compliment their resources in a way that their gains outweigh their losses (sometimes at a later point of time).

\section{Conclusion, discussion, and policy implications}

Pesticide packages discarded on agricultural land can cause land and soil pollution and can contaminate water bodies and hence not only pose a threat to the environment but also to human health. Little is known about how developing countries can deal with this agricultural waste. This paper introduces and analyses a Pesticide Package Collection Scheme in Guangxi Province, China. Implementation of this scheme is the result of an effort of multiple parties, with a private pesticide company as the initiator. Due to tight public finances in Guangxi, the government may not have been able to implement a PPCS, which is why it was comparatively easy for the company to get government support. The company established a scheme that piggy-backs on Guangxi's sugarcane planned economy, and used the sugar processing factories as intermediary. Actors are hence set into relation through both the existing political economic structure of Guangxi's planned sugarcane economy, and the networking efforts of the pesticide company. By employing informal policy instruments like pishi, and by helping local governments to draft Red-head Documents, the company increased its influence in policy-making and therewith shaped future political economic structures. While in principle, also other pesticide companies operating in Guangxi Province could set up a PPCS, at this point, KMK's comparative advantage will be difficult to compete with. This article shows that schemes for collecting pesticide packages can be established even in situations of low economic development. However, the institutionalization of the PPCS in the case at hand has made the government dependent on one particular pesticide company in order to overcome land and soil pollution through pesticide packages. Attention hence needs to be paid to the design of the institutional arrangement underlying such a scheme. This design impacts the kinds of resource dependencies that a scheme establishes. Hereby, it is pivotal that certain actors, and here above all the state, still remain independent and integer in a situation of mutual resource exchange. The state still has to maintain its regulatory role. For example, it is unclear whether the short-term improvement in land pollution happens at the expense of soil pollution in

Table 1

Actors and their resource investments and gains from the Guangxi PPCS.

\begin{tabular}{|c|c|c|c|}
\hline Actor & $\begin{array}{l}\text { Resource } \\
\text { category }\end{array}$ & Investment of own resources & Resource gains/improvements \\
\hline Farmers & $\begin{array}{l}\text { Economic } \\
\text { Socio-political }\end{array}$ & (Effort) Return packages to collection center. & $\begin{array}{l}\text { (Financial) Get paid } 0.10 \mathrm{RMB} / \text { package. } \\
\text { Village coordinators get } 0.06 \mathrm{RMB} / \text { package. } \\
\text { (Environmental) Improvement of land and water environment. } \\
\text { The } 10 \text { farmers who return most of the packages will be awarded honorary credential } \\
\text { by the county leader. }\end{array}$ \\
\hline $\begin{array}{l}\text { Provincial } \\
\text { government }\end{array}$ & Socio-political & $\begin{array}{l}\text { (Political) Leaders' “pishi”. } \\
\text { (Political) Red head documents. } \\
\text { (Time) Participation in meetings. }\end{array}$ & $\begin{array}{l}\text { (Environment) Improvement of land and water environment. } \\
\text { (Political) Gains in reputation/credibility within "Beautiful China" discourse. }\end{array}$ \\
\hline District & Socio-political & $\begin{array}{l}\text { (Political) Leaders' “pishi”. } \\
\text { (Political) Red head documents. }\end{array}$ & $\begin{array}{l}\text { (Environment) Improvement of land and water environment. } \\
\text { (Political) Gains in reputation/credibility within "Clean Rural Guangxi Construction" } \\
\text { discourse. }\end{array}$ \\
\hline \multirow[t]{2}{*}{ KMK } & Economic & $\begin{array}{l}\text { (Financial) Payment of } 0.15-0.20 \mathrm{RMB} / \text { package. } \\
\text { (Financial) Costs for transportation \& training. } \\
\text { (Financial) Payment of } 14,000 \mathrm{RMB} / \mathrm{t} \text { for final } \\
\text { disposal. } \\
\text { (Financial) Advance funds to SPFs and farmers for } \\
\text { pesticides. }\end{array}$ & (Financial) Increased share in Guangxi pesticide market. \\
\hline & Socio-political & & $\begin{array}{l}\text { (Political) Established relationship and good reputation with government. } \\
\text { (Political) Access to decision-makers. } \\
\text { (Social) Increased public reputation. }\end{array}$ \\
\hline \multirow[t]{2}{*}{ SPFs } & Economic & $\begin{array}{l}\text { (Space) Land to establish collection center. } \\
\text { (Labor) Coordinator for package collection. }\end{array}$ & $\begin{array}{l}\text { (Financial) } 0.02 \mathrm{RMB} / \text { package for coordinator. } \\
\text { (Financial) } 0.02 \mathrm{RMB} / \text { package for storage. } \\
\text { (Financial) Reported higher quality of sugarcane. } \\
\text { (Financial) Pesticide costs deducted from revenues. }\end{array}$ \\
\hline & Socio-political & $\begin{array}{l}\text { (Knowledge, Time) Coordination of collection and } \\
\text { training. }\end{array}$ & \\
\hline
\end{tabular}


the long-term, i.e. if the improved collection of pesticide packages through KMK implies a buy-in into more aggressive pesticides. For certain, KMK has obtained an influential position within the pesticide sector of the province, and the kind of pesticides it sells will have a largescale environmental impact.

In the case at hand, KMK's investment in pesticide package collection paid off in many ways, e.g. through political influence but also, ultimately, by increasing its market share. However, the dependency on the pesticide company may come to the disadvantage of the natural environment and of political integrity. If a pesticide company took the initiative to establish a PPCS in other contexts, the government may involve, at a certain stage, other pesticide companies in the setting up of such a scheme. This would ensure that collection structures are not too reliant on one particular pesticide company. Furthermore, those who are involved would to some extent benefit from establishing such structures, by expanding their client base. However, increases in benefits would remain relatively low in comparison to KMK's gains.

In China, pesticide packages are defined as hazardous waste by law, with strict requirements on transportation and disposal, which implies that the disposal of pesticide packages is costly. In order to avoid dependency on one pesticide company, national law would at least need to stipulate the compulsory collection of pesticide packages for all companies. This may not always need to come at as high costs as in the case at hand. This research, but also similar studies in Hebei Province (see Wei and Jin, 2016), show that farmers are willing to return empty packages even without subsidy, since they see environmental improvements after several years of PPCS implementation. In the case of Hebei, even if there was no PPCS program, farmers still wanted to return empty packages if it did not imply too much effort (Wei and Jin, 2016). One further, more hands-on, bottleneck for collecting pesticide packages is hence the setting up of a collection spot that is convenient for farmers to return the packages to.

While in the case at hand, Guangxi's particular political economy made it easier for the pesticide company to reach out to farmers because SPFs play a crucial role as a mediator between KMK and smallholders, in other contexts, actors that could take over a similar coordinating role would be cooperatives, agricultural service companies or large agricultural companies with contracted farmers. Through cooperating with those actors, pesticide companies do not need to directly interact with thousands of smallholders and hence reduce their transaction costs in collecting the packages.

\section{Funding}

This research was carried out within the research project SURE (Sustainable Natural Resource Use in Rural China), which is funded by the Royal Netherlands Academy of Arts and Sciences(KNAW), grant 08PSA-E-02, and the Chinese Ministry of Science and Technology (MoST), grant 2008DFA90630, as part of the Program Strategic Scientific Alliances. This research was also supported by the project "Integrated Technology on Reducing Chemical Fertilizers and Pesticides" (grant 2016ZY0600374704) under the frame of National Key Research and Development Program of China.

\section{Acknowledgements}

We would like to thank the anonymous reviewers for their valuable comments.

\section{References}

Al Zadjali, S., Morseb, S., Chenoweth, J., Deadman, M., 2013. Disposal of pesticide waste from agricultural production in the Al-Batinah region of Northern Oman. Sci. Total Environ. 463-464, 237-242.

Arts, B., van Tatenhove, J., 2004. Policy and power: a conceptual framework between the "old" and "new" policy idioms. Policy. Sci. 37, 339-356.
Arts, B., Leroy, P., van Tatenhove, J., 2006. Political modernisation and policy arrangements: a framework for understanding environmental policy change. Public Organ. Rev. 6, 93-106.

Augustin-Jean, L., 2014. China's sugar under globalization forces: market structures and state decision making in the context of liberalization. In: Augustin-Jean, L., Alpermann, B. (Eds.), The Political Economy of Agro-food Markets in China. Palgrave Macmillan, New York, pp. 103-126.

Bluemling, B., Pahl-Wostl, C., Mosler, H.-J., Yang, H., 2010. Implications of stakeholder constellations for irrigation at jointly used wells cases from the North China Plain, China. Soc. Nat. Resour. 23 (6), 557-572.

Brandsen, T., 2001. Bringing actors back in: towards an institutional perspective. Hous. Theory Soc. 18 (1-2), 2-14.

Cai, J., 2013. Pesticide packaging waste recycling: support attitude and mode selection. Res. Econ. Manag. 12:67-74. https://doi.org/10.3969/j.issn.1000-7636.2013.12.009 (in Chinese).

Dai, J., Dong, H., 2014. Intensive cotton farming technologies in China: achievements, challenges and countermeasures. Field Crop Res. 155, 99-110.

Dalvie, M.A., Africa, A., London, L., 2006. Disposal of unwanted pesticides in Stellenbosch, South Africa. Sci. Total Environ. 361, 8-17.

Damalas, C.A., Telidis, G.K., Thanos, S.D., 2008. Assessing farmers' practices on disposal of pesticide waste after use. Sci. Total Environ. 390, 341-345.

FAO/WHO, 2008. International Code of Conduct on the Distribution and Use of Pesticides, Guidelines on Management Options for Empty Pesticide Container (Rome).

He, Z., Jin, S., 2013. Institutional arrangements and pattern for pesticide packaging wastes collection: a comparative analysis of international experiences. World Agric. 12: 35-39. https://doi.org/10.3969/j.issn.1002-4433.2013.12.008 (in Chinese).

Hu, Z., Rahman, S., 2015. Beyond a bottle of liquid: pesticide dependence in transitional rural China. Local Environ. https://doi.org/10.1080/13549839.2015.1050657.

InpEv-National Institute for Processing Empty Containers, 2011. Campo Limpo System. available from. http://www.inpev.org.br/en/campo-limpo-system/index (Search date: 08-07-2015).

Jiao, S., Shan, Z., Cai, D., Xu, H., 2012. Caution the rubbish on the farming land: suggestions on pesticide packages management. Environ. Prot. 18, 42-44 (in Chinese).

Jin, S., Bluemling, B., Mol, A.P.J., 2015. Information, trust and pesticide overuse: interactions between retailers and cotton farmers in China, NJAS - Wageningen. J. Life Sci. $72-73,23-32$.

KMK, 2013. A review of the pesticide containers collection program in Laibin, Guangxi. pp. 2011.6-2013.5 (in Chinese. KMK, Guangxi).

KMK, 2014. A Report on Pesticide Containers Collection and Treatment in Guangxi. (in Chinese. KMK, Guangxi)

Kumar, R., 2005. Research Methodology: A Step-by-step Guide for Beginners. SAGE Publications Ltd, London.

Li, J., Bluemling, B., Mol, A.P.J., Herzfeld, T., 2014. Stagnating Jatropha biofuel development in Southwest China: an institutional approach. Sustain. For. 6, 3192-3212.

Liu, E.M., Huang, J., 2013. Risk preferences and pesticide use by cotton farmers in China. J. Dev. Econ. 103, 202-215.

Liu, E.K., He, W.Q., Yan, C.R., 2014. 'White revolution' to 'white pollution' - agricultural plastic film mulch in China. Environ. Res. Lett. 9, 091001.

Mengiste, B., Oosterveer, P., Mol, A.P.J., 2015. Information, motivation and resources: the missing elements in pesticide policy implementation in Ethiopia. Int. J. Agric. Sustain. 31, 240-256.

Mengiste, B., Mol, A.P.J., Oosterveer, P., 2016. Private environmental governance in the Ethiopian pesticide supply chain. NJAS-Wageningen J. Life Sci. 76, 65-73.

National Bureau of Statistics of China, 2014. China Statistical Yearbook 2014. China Statistics Press.

Nonga, H.E., Mdegela, R.H., Lie, E., Sandvik, M., Skaare, J.U., 2011. Assessment of farming practices and uses of agrochemicals in Lake Manyara basin, Tanzania. Afr. J. Agric. Res. 6, 2216-2230.

People's Government of the Guangxi Zhuang Autonomous Region, 2011. The 12th Five Year Plan for Economic and Social Development of Guangxi. http:// www.gxzf.gov.cn/zwgk/fzgh/ztgh/201105/t20110524_323633.htm (search date: 28-09-2015).

Scharpf, F.W., 2000. Interaktionsformen Akteurzentrierter Institutionalismus in der Politikforschung. Leske + Budrich, Opladen.

State Council of China, 2013. Work Arrangement for Soil Environment Protection and Comprehensive Management in the Near Future. http://www.gov.cn/zwgk/201301/28/content_2320888.htm (search date: 28-09-2015).

Sun, B., Zhang, L., Yang, L., Zhang, F., Norse, D., Zhu, Z., 2012. Agricultural non-point source pollution in China: causes and mitigation measures. Ambio 41, 370-379.

Van Hoi, Pham, Mol, A.P.J., Oosterveer, P., van den Brink, P., 2009. Pesticide distribution and use in vegetable production in the Red River Delta of Vietnam. Renewable Agric. Food Sys. 24, 174-185

Wang, Y., Wang, Y., Huo, X., Zhu, Y., 2015. Why some restricted pesticides are still chosen by some farmers in China? Empirical evidence from a survey of vegetable and apple growers. Food Control 51, 417-424.

Wei, X., Jin, S., 2014. Collecting pesticide packaging wastes: practices in Shanghai. Rev. Econ. Res. 59, 70-72 (in Chinese)

Wei, X., Jin, S., 2016. Collection for Pesticide Packaging Wastes: Theories, Patterns, and Practice. Press of Chemical Industry, Beijing (in Chinese).

Yan, H., 2014. Why Chinese Farmers Obey the Law - Pesticide Compliance in Hunan Province, China. University of Amsterdam, PhD Dissertation.

Zhang, C., Hu, R., Shi, G., Jin, Y., Robson, M.G., Huang, X., 2015. Overuse or underuse? An observation of pesticide use in China. Sci. Total Environ. 538, 1-6. 